\title{
The Microenvironment Effect on the Generation of Reactive Oxygen Species (ROS) by Pd-Bacteriopheophorbide
}

Yahel Vakrat-Haglili ${ }^{1}$, Lev Weiner ${ }^{3}$, Vlad Brumfeld ${ }^{1}$, Alexander Brandis ${ }^{1}$, Yoram Salomon ${ }^{2}$, Brian Mcllroy ${ }^{4}$, Brian Wilson ${ }^{4}$, Anna Pawlak ${ }^{5}$, Malgorzata Rozanowska , Tadeusz Sarna ${ }^{5}$ and Avigdor Scherz**

\footnotetext{
${ }^{1}$ Department of Plant Sciences, Weizmann Institute of Science, Rehovot, Israel.

${ }^{2}$ Department of Biological Regulation, Weizmann Institute of Science, Rehovot, Israel.

${ }^{3}$ Department of Chemical Services, Weizmann Institute of Science, Rehovot, Israel.

${ }^{4}$ Ontario Cancer Institute, Princess Margaret Hospital, Toronto, Canada.

${ }^{5}$ Faculty of Biotechnology, Jagiellonian University, Krakow, Poland.
}

INDEX

page

\section{Materials and methods}

$\begin{array}{lr}\text { Materials (1) } & 2\end{array}$

ESR spectroscopy (2) 3

ESR oximetry (3) 3

Time-resolved spectroscopy (4) 3

Optical absorption (5) 5

$\begin{array}{ll}\text { Phosphorescence Spectra (6) } & 5\end{array}$

$\begin{array}{ll}\text { Photochemical degradation (7) } & 5\end{array}$

$\begin{array}{lr}\text { Figure } 1 & 7\end{array}$

Figure 2

$\begin{array}{lr}\text { Figure } 3 & 9\end{array}$

$\begin{array}{lr}\text { Figure } 4 & 10\end{array}$

$\begin{array}{ll}\text { Figure } 5 & 11\end{array}$ 


\section{Materials and methods}

\section{Materials (1)}

Pd-Bpheid (1a) was synthesized as previously described ${ }^{1,2}$. 5,5-dimethyl-1-pyrroline- N-oxide (DMPO), 2,2,6,6-tetramethyl-4-piperidone hydrochloride (TEMP), superoxide dismutase (SOD), catalase, 1,4-diazabicyclo-[2,2,2]-octane (DABCO), deuterium oxide $\left(\mathrm{D}_{2} \mathrm{O}, 99.9 \%\right.$ pure deuterium), $1-\alpha-$ phospatidyl-choline Dimyristoyl (1-2-DMPC, 99\%, synthetic), Diethylenetriaminepenta-acetic acid (DTPA), Triton X-100, Chelex X-100, Phosphate buffered saline (PBS) without calcium chloride and magnesium chloride, 1,1-diphenyl-2-picryl hydrazyl (DPPH), sodium azide $\left(\mathrm{NaN}_{3}\right)$, $\beta$-carotene, and histidine were purchased from Sigma. 2,2,5,5, tetramethyl 3-pyrrolin-1-oyl-3-carboxylic acid (a free radical) was a gift from Prof. M. Sheves (Weizmann Institute), and 4-protio-3-carbamoyl-2,2,5,5tetraperdeuteromethyl-3-pyrroline-1-yloxy (mHCTPO) was a gift from Prof. H.J. Halpern (University of Chicago, Chicago, IL) and used as received. 5-Diethoxyphosphoryl-5-methyl-1-pyrroline-N-oxide (DEPMPO) was obtained from Calbiochem-Novabiochem Corporation (Germany). Non-saturated liposome Phosphatidylcholine (PC) was made of Lecithin from egg yolk (grade 1), Lipid Products (England).

Liposomes from DMPC or PC were prepared in two steps: (1) a solution of 5mg of Lecithin in 2:1 Chloroform:Methanol, together with $0.5 \mathrm{ml}$ of Pd-Bpheid in Chloroform (final optical absorbance of 7) was dried under a slow nitrogen flow until a thin lipid/pigment film was formed on the bottom of the flask. After evaporation, the mixture was kept under Argon. Then, the dry lipid-pigment film was suspended in $0.5 \mathrm{ml}$ PBS (free of $\mathrm{Ca}$ and $\mathrm{Mg}$ by pretreatment with chelating Resin (chelex X-100)). DTPA (1mM) was added to the Chelexed PBS. The suspension was sonicated on ice with Ultrasonics W-380 for $5 \mathrm{~min}$. For the ESR measurements, $50 \mu \mathrm{l}$ of the liposome preparation was transferred to a flat cell, together with $60 \mu 1$ of PBS solution that contained the spin trap (i.e. DMPO, TEMP). 
ESR spectroscopy (2) with spin traps was carried out using a Bruker EPR 200 D-SRC or ES300E spectrometer, under standard conditions (The spectrometer was operated at $9.78 \mathrm{GHz}$, microwave power-20mW, modulation amplitude-1Gauss, time constant-640ms, scan range-100 G, scan time 200 sec). The Pd-Bpheid concentration was adjusted to $\sim 26 \mu \mathrm{M}$ in most experiments. The optical absorption of each sample was recorded before and after the EPR measurement. Spectra simulation was done by NIEHS P.E.S.T. Winsim Simulation Software.

ESR oximetry (3) To monitor oxygen consumption, as an indicator of a photosensitized oxidation reaction, we employed ESR oximetry using $\mathrm{mHCTPO}$ as a spin probe ${ }^{3}$ and histidine as the photooxidation substrate. Air-saturated samples, containing Pd-Bpheid in Triton $\mathrm{X}-100 / \mathrm{D}_{2} \mathrm{O}, 2 \mathrm{mM}$ histidine, and a nitroxyl spin probe $(0.1 \mathrm{mM} \mathrm{mHCTPO})$, were irradiated in situ in a ESR resonant cavity for given time intervals with concomitant recording of the ESR spectra of the spin probe.

Time-resolved spectroscopy (4) was performed in two time domains. Measurement in the sub-micro to the millisecond time domains were performed using a Q-switched Nd:YAG laser (Surelite II; Continuum) as the excitation source (5-ns pulses of a second, $532 \mathrm{~nm}$, or a third, $355 \mathrm{~nm}$, harmonic). The output energy was changed with a Q-switch and neutral density filters and was up to $120 \mathrm{~mJ}$ per pulse. The laser energy was monitored using a GenTec (model ED-200L) energy meter. The optical density of the samples at the excitation wavelengths was in the range $0.05-0.20$ for a $1 \mathrm{~cm}$ path length unless stated otherwise. Transient bleaching and transient species absorbance were monitored using a 75-W compact arc xenon lamp (PTI Photon Technology International; LPS-200 Lamp Power Supply) as a monitoring light source, a monochromator (Spectra Pro-275, Acton Research Corporation) and a photomultiplier (Hamamatsu Photonics K.K. R928 - to monitor transient absorption changes in the UVVIS region and Hamamatsu Photonics K.K. R 5108 to monitor such changes in the NIR region) with a power supplier (PS325, Stanford Research) coupled to a Tektronix digitizing scope (TDS 520B) interfaced with a PC computer. To prevent the degradation of the sample due to excessive irradiation by a monitoring lamp, a shutter (D122, UniBlitz) was used. The singlet oxygen characteristic 
phosphorescence at $1270 \mathrm{~nm}$ was probed by a nitrogen-cooled germanium detector (North Coast Scientific Corporation EO-817P). Silicon cut-off filters transmited light above $1100 \mathrm{~nm}$ and interference filters transmited light around $1270 \mathrm{~nm}$ for cutting out stray light. A home-build sequence generator was used to trigger the sequence of events, and special, custom-written software was used for data collection and analyses.

Measurements in the pico-nano second time domain were performed with $\approx 40 \mu \mathrm{M}$ Pd-Bpheid in acetone, chloroform, TX-100 micelles or liposomic aqueous solutions prepared as described $\left(\mathrm{OD}_{760 \mathrm{~nm}} \approx 0.9\right.$ in a $2-\mathrm{mm}$ quartz cuvette sealed with a Teflon stopper to prevent solvent evaporation $)$, using a pump-probe setup. The sample was excited at $765 \mathrm{~nm}$ by $14-\mathrm{ps}, 90-\mathrm{mJ}$ pulses generated from a Continuum PD10 dye laser (Coherent) that was pumped by a frequency-doubled Nd:YAG laser (Quantel, 532nm, $38 \mathrm{ps}$ ). White light pulses $(480-860 \mathrm{~nm})$, generated by focusing the residual fundamental beam (1064 nm, 38 ps) of the Nd-YAG laser on a 5-cm path length cylindrical water cell were used for probing. The pump-probe interval was controlled by an optical delay line. Spectra were detected using a double diode array (DIDA 512), with dedicated software (Winspec), all from Princeton Instruments. Pump pulse intensity was monitored by a power meter (Coherent LabMaster). The measurement was carried out at a right angle with the pump pulse, having an accuracy of about \pm 0.01 absorbance units.

Optical absorption (5) was monitored by a Spectronic GENESYS (Milton Roy) or a Jasco V-570 or Hewlett Packard 8453 spectrophotometers.

Phosphorescence Spectra (6) were monitored using a MB-157 2E FTIR machine (Quebec, Canada) adapted for phosphorescence measurements at the Photonics Research Ontario Facility of the University of Toronto. The setup was equipped with a 1.5-mW, 532-nm double Nd:YAG laser for excitation. The system includes an InGaAs detector with good sensitivity, a high signal-to-noise ratio over the 1-2 $\mu \mathrm{m}$ range of interest and was corrected for the response of the detector. The excitation light was focused into a long nosed $1 \mathrm{~cm}$-pathlength-quartz cuvette (NSG Precision Cells, Inc., Farmingdale, NY, USA) 
holding the solution, and the resulting emission was collected off a parabolic mirror and focused onto the entrance slit of the FTIR. The controlling software allowed alignment as well as signal averaging. All spectra were averaged over 100 runs with a resolution of $16 \mathrm{~cm}^{-1}$. The fundamental 1064-nm line was used for wavelength reference. The spectra could provide relative intensities only. Optimization and alignment of the signal was done under aerobic conditions using the singlet oxygen emission at $1270 \mathrm{~nm}$ as a reference.

Photochemical degradation (7) of Pd-Bpheid in 3\% TX-100/PBS/Chelexed solution was induced by 778-nm, 15-mW continuous illumination (using the aforementioned home-built diode laser) under aerobic conditions. The degradation progress was monitored by the sample optical absorption at $760 \mathrm{~nm}$ using the Jasco V-570 spectrophotometer (at a scanning mode of $1000 \mathrm{~nm} / \mathrm{min}$ ). The laser beam was applied at a right angle from above the cuvette. Generation of photo-products was monitored by an absorption increase at 660 and $600 \mathrm{~nm}$. The major reaction products were separated by HPLC and characterized by Electro Spray Ionization-Mass Spectroscopy (ESI-MS) (platform LCZ spectrometer, micromass, England), as recently described for purification of Pd-Bpheid ${ }^{1,2}$. All studied solutions were treated with Chelex resin X-100 for $24 \mathrm{~h}$.

2001.

(1) Scherz, A.; Salomon, Y.; Scheer, H.; Hartwich, G.; Brandis, A. US patent 6,333,319

(2) Scherz, A.; Salomon, Y.; Brandis, A.; Scheer, H. US patent 6,569,846 2003.

(3) Rozanowska, M.; Bober, A.; Burke, J.; Sarna, T. Photochem. Photobiol. 1997, 65(3), 472-479. 


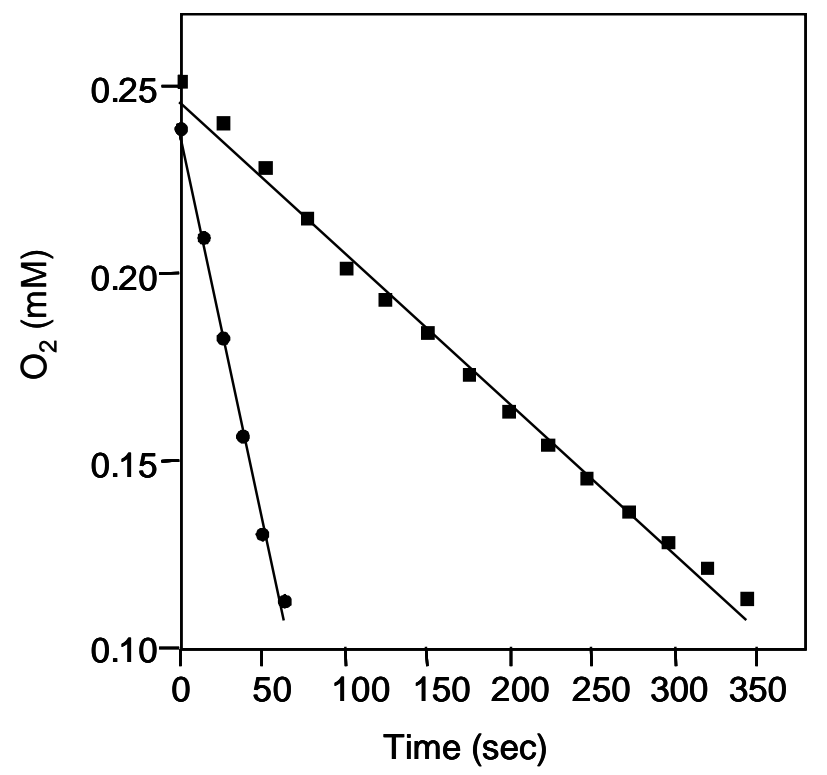

Figure 1: Oxygen photo-uptake induced by irradiation of Pd-Bpheid in TX-100 micelles/ $\mathrm{D}_{2} \mathrm{O}$ with 760 $\mathrm{nm}$ light in the presence of $2 \mathrm{mM}$ histidine with (in squares) and without (in circles) $10 \mathrm{~m} \mathrm{M}$ of sodium azide. Oxygen concentration changes were determined by ESR oxymetry using mHCTPO (spin label). 


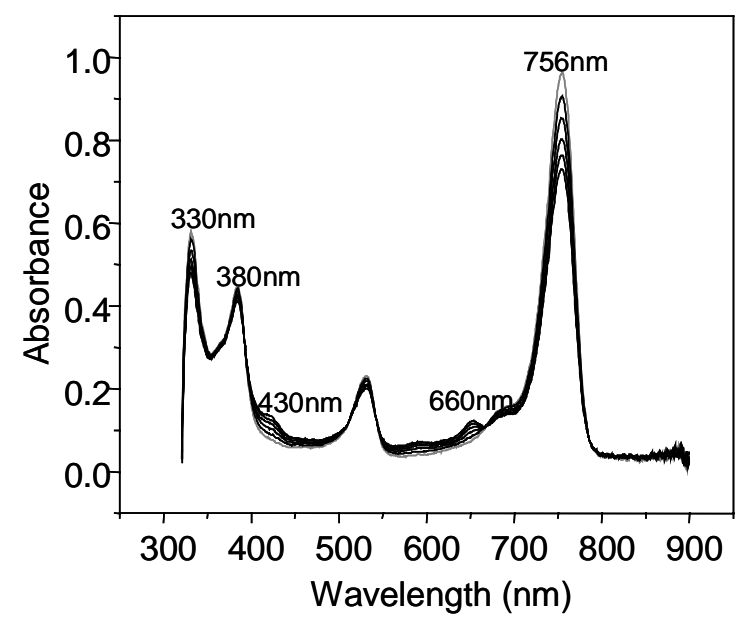

Figure 2. Absorption changes of Pd-Bpheid $(46 \mu \mathrm{M})$ during illumination $(778 \mathrm{~nm}, 13 \mathrm{~mW})$ in acetone under aerobic conditions (degradation of peaks at 330, 380, 532, and $756 \mathrm{~nm}$, formation of peaks at 430, $660 \mathrm{~nm})$. 


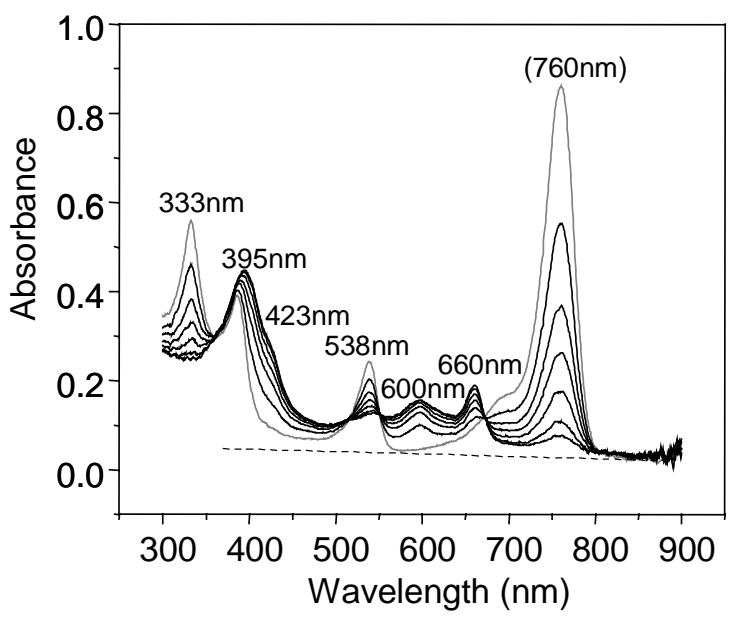

Figure 3. The formation of Pd-Bpheid's photochemical products in 3\% Triton X-100/Chelexed PBS upon illumination. Absorbance spectra show the degradation products at 760, 538, 395, and $333 \mathrm{~nm}$ and the formation of new photoproducts at $660,600,423$, and $395 \mathrm{~nm}$. 


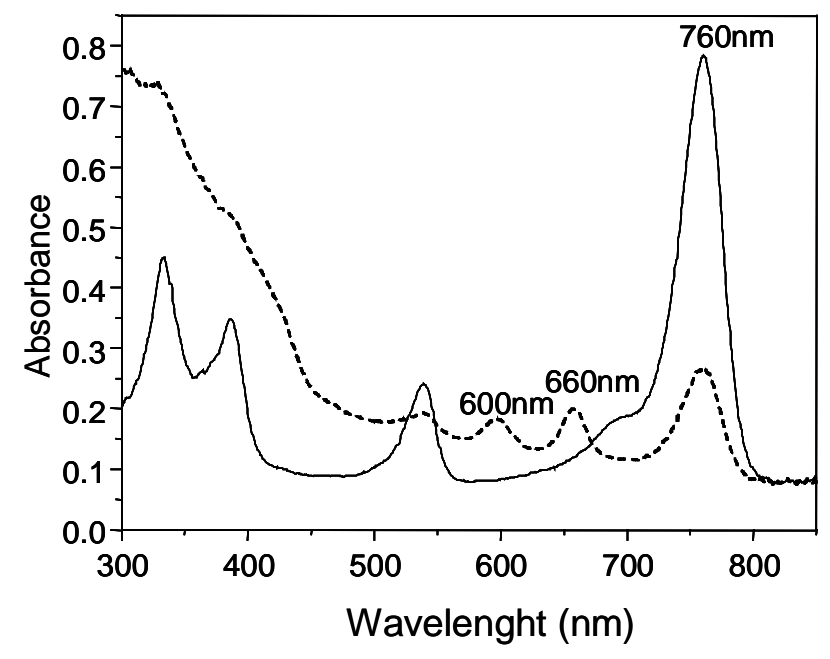

Figure 4. Pd-Bpheid in 1.5\% TX-100/Chelexed PBS in the dark (full line) and its degradation in the presence of $\mathrm{OH}$ radicals formed by the Fenton Reaction $\left(\mathrm{H}_{2} \mathrm{O}_{2}(1 \mathrm{mM})+\mathrm{FeSO}_{4}(1 \mathrm{mM})\right)$ (dashed line). 


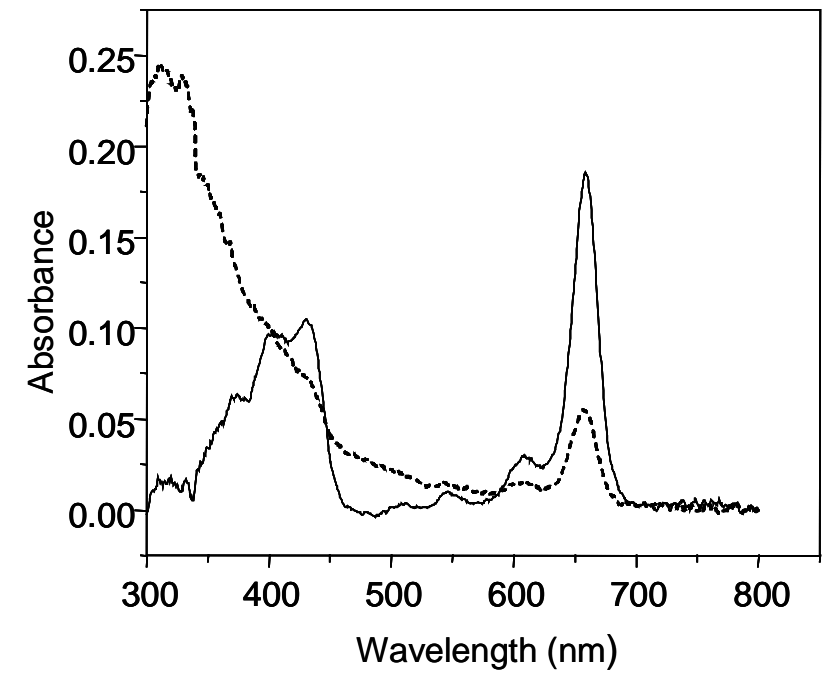

Figure 5. Pd-2-Ac-Pheid in 1.5\% TX-100/Chelexed PBS in the dark (full line) and its degradation in the presence of $\bullet \mathrm{OH}$ radicals formed by the Fenton Reaction $\left(\mathrm{H}_{2} \mathrm{O}_{2}(1 \mathrm{mM})+\mathrm{FeSO}_{4}(1 \mathrm{mM})\right)$ (dashed line). 